\title{
Alternative tissue engineering scaffolds based on starch: processing methodologies, morphology, degradation and mechanical properties
}

\author{
M.E. Gomes*, J.S. Godinho, D. Tchalamov, A.M. Cunha, R.L. Reis \\ Department of Polymer Engineering, University of Minho, Campus de Gualtar, 4710-057 Braga, Portugal
}

\begin{abstract}
An ideal tissue engineering scaffold must be designed from a polymer with an adequate degradation rate. The processing technique must allow for the preparation of 3-D scaffolds with controlled porosity and adequate pore sizes, as well as tissue matching mechanical properties and an appropriate biological response. This communication revises recent work that has been developed in our laboratories with the aim of producing 3-D polymeric structures (from starch-based blends) with adequate properties to be used as scaffolds for bone tissue engineering applications. Several processing methodologies were originally developed and optimised. Some of these methodologies were based on conventional melt-based processing routes, such as extrusion using blowing agents (BA) and compression moulding (combined with particulate leaching). Other developed technologies included solvent casting and particle leaching and an innovative in situ polymerization method. By means of using the described methodologies, it is possible to tailor the properties of the different scaffolds, namely their degradation, morphology and mechanical properties, for several applications in tissue engineering. Furthermore, the processing methodologies (including the blowing agents used in the melt-based technologies) described above do not affect the biocompatible behaviour of starch-based polymers. Therefore, scaffolds obtained from these materials by means of using one of the described methodologies may constitute an important alternative to the materials currently used in tissue engineering. (C) 2002 Elsevier Science B.V. All rights reserved.
\end{abstract}

Keywords: Starch-based polymers; Tissue engineering; Biodegradable scaffolds

\section{Introduction}

The advent of tissue engineering has been motivated by the challenge of producing tissue substitutes that can restore the structural features and physiological functions of natural tissues in vivo [1,2], circumventing the limitations of current therapies for tissue malfunctioning or tissue loss. Tissue engineering is an interdisciplinary science that combines the knowledge of distinct fields, from biology to materials science and engineering, to obtain hybrid materials to use in substitution medicine. In most cases, biocompatible, degradable polymers are utilised to induce surrounding tissue ingrowth or to serve as temporary scaffolds for transplanted cells to attach, grow and maintain differentiated functions [2-7], which then degrade as the new tissue is formed.

These materials must comply with a large number of requirements. Besides the obvious demand of biocompatibility and biodegradability, they should have other properties such as the appropriate mechanical properties to provide the

\footnotetext{
* Corresponding author. Tel.: +351-253604491; fax: +351-253604492.

E-mail address:megomes@dep.uminho.pt (M.E. Gomes).
}

correct stress environment for the neo tissue [1,5,8-14], the adequate degradation rate that assures that the strength of the scaffolds is retained until the newly grown tissue takes over the synthetic support $[2,5,10,12-15]$, the adequate porosity and permeability in order to allow the ingress of cells and nutrients $[5,8,12-15]$, and the appropriate surface chemistry for enhanced cell attachment and proliferation $[3,5,12$, 13,16-18]. Until now, several natural and synthetic polymers have been investigated to be used as scaffold materials, but only a very small number is being clinically used in a limited range of tissue engineering applications.

The first stage of tissue engineering, and one of the most important ones, is the design and processing of a porous 3-D scaffold with an interconnected structure of well-distributed pores with appropriate sizes for cell seeding [19]. The methods of manufacturing such scaffolds in a reproducible manner are crucial to their success and should allow for the necessary scaleup of the developed tissue engineering technology $[4,8]$. The technique used to manufacture scaffolds for tissue engineering must allow the preparation of scaffolds with complex three-dimensional geometries and adequate porous structure, without affecting the biocompatibility of the material $[3,20]$. 
In this work, several methods based on conventional processing techniques and combined techniques, such as solvent casting and compression with salt leaching, were developed in order to obtain porous structures from starchbased polymers that are suitable for bone tissue engineering applications. The scaffolds obtained by the different methods exhibit different structure/property combinations that may constitute a promising alternative to currently used biodegradable scaffolds.

\section{Materials and methods}

In this study, two different polymeric blends of corn starch with: (i) ethylene vinyl alcohol blends (SEVA-C) and (ii) cellulose acetate (SCA), both obtained from Novamont, Italy, were used.

Several blowing agents (BA) were selected for the present study. The first blowing agent selected was Hostatron System P9947, from Hoechst, Germany, which will be designated as blowing agent 1 (BA1). This blowing agent of commercial origin is mainly composed of carboxylic acid that reacts by heating, releasing $\mathrm{CO}_{2}$ and water at about $200{ }^{\circ} \mathrm{C}$. Two other blowing agents were selected, namely Hydrocerol BIH 70 and Hydrocerol BIH 40, which will be designated by blowing agent 2 (BA2) and blowing agent 3 (BA3), respectively; both were obtained from Clariant, Germany. These blowing agents are based on citric acid and they also release $\mathrm{CO}_{2}$ and water upon decomposition, which happens around $170{ }^{\circ} \mathrm{C}$. The cytotoxicity of these materials has been tested [21] and the results show a noncytotoxic behaviour.

\subsection{Extrusion with blowing agents}

In the extrusion process, the polymers were previously mixed with the blowing agents in a biaxial rotating drum prior to processing in a twin-screw extruder Carvex, with a die of $12 \mathrm{~mm}$ in diameter. This process was optimised for mixtures of the polymer with $10 \%$ and $15 \%(\mathrm{w} / \mathrm{w})$ of blowing agent 1 . The weight fraction of blowing agents 2 and 3 necessary to produce the same percentage of porosity was much smaller than the one used with BA1 (between $1 \%$ and $2.5 \%$ ).

\subsection{Compression moulding-particle leaching}

The compression moulding and particle leaching method was based on blending together a starch-based polymer (in the powder form) and leachable particles (in this case, salt particles) of different sizes, from 50 to $1000 \mu \mathrm{m}$, in sufficient amounts to provide a continuous phase of a polymer and a dispersed phase of leachable particles in the blend. The blend was then compression moulded into a desired shape. The mould used was specially designed for this purpose and allowed to obtain discs of $6 \mathrm{~cm}$ in diameter and approx- imately $1 \mathrm{~cm}$ in height. The resultant samples were then immersed in distilled water to remove the leachable particles. In all the methods combined with salt leaching described in this manuscript, the leaching procedure was optimised for "excess leaching" of the salt.

\subsection{Solvent casting-particle leaching}

For the development of the solvent casting and particle leaching method, it was necessary to find a solvent capable of dissolving properly the starch-based polymers once it was found that due to its complex structure (and high molecular weight of the starch), these materials were not soluble without degradation in the traditional organic solvents. After performing an all range of solubility tests using several solvents, it was found that at least four solvents were able to dissolve these polymers, namely acetic acid, dimethylformamide and dimethyl sulfoxide. The results shown in this manuscript are referred to starch with cellulose acetate (SCA) dissolved in acetic acid, from Merck, Germany. With this method, the polymers were first dissolved in an appropriate organic solvent and mixed with salt particles of different sizes. In general, it was added a salt weight fraction of 60$70 \%$ (based on the total mass of polymer and salt). The size of the particles used ranged from 50 to $1000 \mu \mathrm{m}$. The mixture of the polymeric solution with the salt particles was then poured into a mould (a glass petridish of $3 \mathrm{~cm}$ in diameter) and placed in an oven at $37{ }^{\circ} \mathrm{C}$ in order to allow a progressive evaporation of the solvent. Finally, when the samples were completely solidified, they were immersed in distilled water for leaching of the salt particles and dried afterwards.

\subsection{In situ polymerization}

This innovative so-called in situ polymerization process was based on a polymerization process developed in our group in order to obtain materials to be used as bone cements or hydrogels [22].

These materials were prepared by adding the liquid phase, constituted by the acrylic monomers (AA, from Merck) and $1 \%(\mathrm{w} / \mathrm{w})$ of $N$-dimethylaminobenzyl alcohol (DMOH), which was used as the activator of the initiation process, to the solid phase, which consisted of SEVA-C powder and $2 \%$ (w/w) of benzoic peroxide (BPO, from Merck), which was used as the radical initiator after purification by fractional recrystallization from ethanol, mp $104{ }^{\circ} \mathrm{C}$ BPO. The leachable $\mathrm{NaCl}$ particles were added to the liquid or to the solid phase in order to provide the porosity of the structure. The solid and the liquid phases are then mixed together with $10 \%$ of water with respect to the total weight and poured in a dough state in poly(tetrafluoroethylene) (PTFE) moulds until complete polymerization take place.

After curing time, about $5 \mathrm{~min}$, the moulds were placed into the oven at $60{ }^{\circ} \mathrm{C}$ overnight to ensure a complete polymerization and then vacuum dried until constant weight was attained. Finally, the samples were immersed in water to 
leach out the salt particles in order to better simulate the in vivo application of these materials.

\subsection{Materials characterization}

The porous structure of the materials developed, namely the morphology of the pores, their size and distribution, and also the interconnectivity between these pores, was characterised by scanning electron microscopy (SEM), in a Leica Cambridge S360. All the samples were previously goldcoated in a Sputter Jeol JFC 1100 equipment. The porosity measurements were obtained from the photographs acquired by SEM that were processed using an image analysis software.

The mechanical properties of the developed materials were assessed on compressive experiments in an Instron 4505 universal mechanical testing machine, using a load cell of $50 \mathrm{kN}$. The compression tests were carried out at a crosshead speed of $2 \mathrm{~mm} / \mathrm{min}\left(4.7 \times 10^{-5} \mathrm{~m} / \mathrm{s}\right)$, until obtaining a maximum reduction in samples' height of $60 \%$. A minimum of six samples of each type was tested.

The degradation behaviour was assessed after several prefixed ageing periods $(0.3,7,14,30,60$ and 90 days) in an isotonic saline solution $(\mathrm{NaCl}, 0.154 \mathrm{M})$. At the end of each degradation period, the samples were removed from the solution, rinsed with distilled water and weighted, to determine the water uptake; one batch of samples was then dried up to exhaustion (6 days at $60{ }^{\circ} \mathrm{C}$ ) in order to determine the dry weight loss.

\section{Results and discussion}

\subsection{Morphology of the porous structures}

\subsubsection{Extrusion with blowing agents}

The porous structure of the samples obtained by extrusion of the polymers combined with blowing agents results from the gases released by decomposition of the BA during processing. Therefore, it is difficult to control the pore size and the interconnectivity between the pores. However, a thin layer of solid material (less than $1 \mathrm{~mm}$ in 12-mm-thick samples) surrounds the porous structure of the material.

The extrusion process using blowing agent 1 (Fig. 1) produces samples with pore sizes roughly between 50 and 300 $\mu \mathrm{m}$, but the interconnectivity of the porous structure obtained is still very poor, even with the use of the surfactant agents.

In Figs. 2 and 3, it can be seen that by means of using blowing agents 2 and 3 (in both cases Hydrocerols), it was possible to obtain higher porosity and significant improvements with respect to the interconnectivity of the porous structures. This becomes much more evident in Fig. 3 that corresponds to the materials obtained using the blowing agent 3. Furthermore, such increase in the porosity was obtained using much lower amounts of blowing agent (about 2 wt.\%). In this case, the pore sizes are in the range of $100-500 \mu \mathrm{m}$, a range that includes the values that are believed to give the best results in terms of bone cell culture and bone tissue ingrowth by several experts [23-25]. The density of the samples obtained by this process is approx-

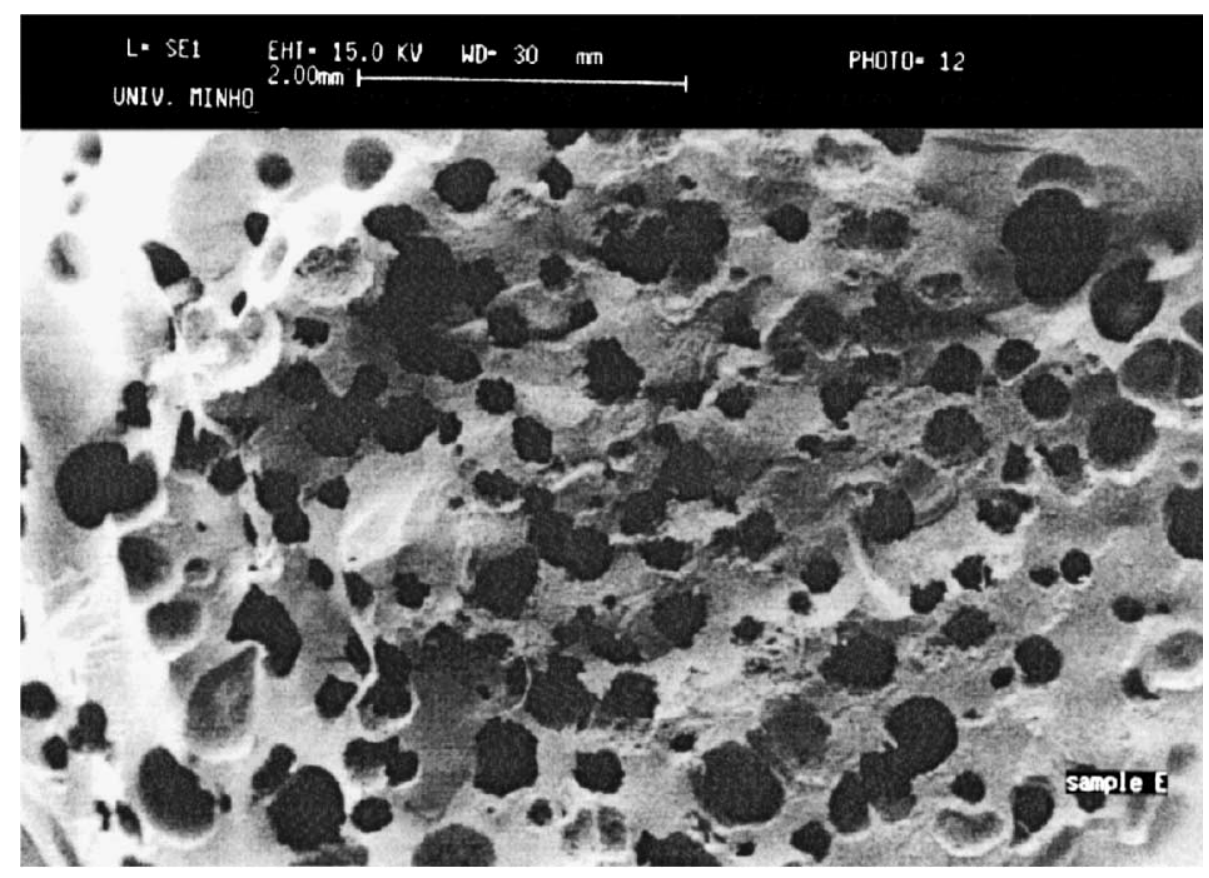

Fig. 1. Scaffold obtained by of SCA extrusion of SCA with $10 \%$ of blowing agent 1 (Hostatron 9947). 


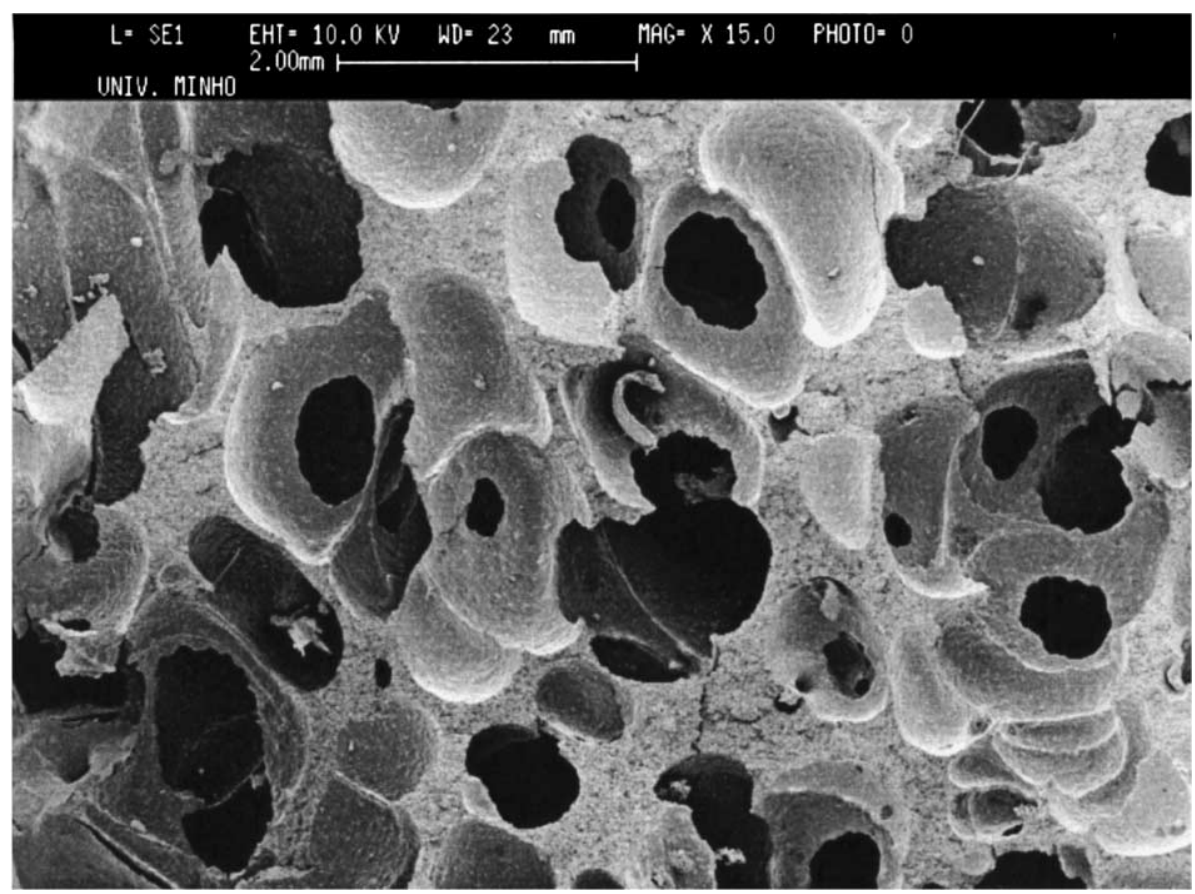

Fig. 2. SCA scaffold obtained by extrusion of SCA with $2.5 \%$ of blowing agent 2 (Hydrocerol BIH 70 ).

imately $0.7-0.8 \mathrm{~g} / \mathrm{cm}^{3}$ (depending mainly on the blowing agent used), leading to a porosity of about $40-50 \%$.

\subsubsection{Compression moulding and particle leaching}

The compression moulding-particle leaching technique gives rise to structures consisting in an open network of pores throughout the sample (see Fig. 4), with sizes ranging from 10 to $500 \mu \mathrm{m}$. The pores showed a large degree of interconnection, which is very important for cell seeding and growth. These scaffolds present a density of about $0.7 \mathrm{~g} /$ $\mathrm{cm}^{3}$, leading to a porosity of about $50 \%$. With this technique, it is possible to control the percentage of porosity and the pore size by simply varying the amount and size of the leachable particles.

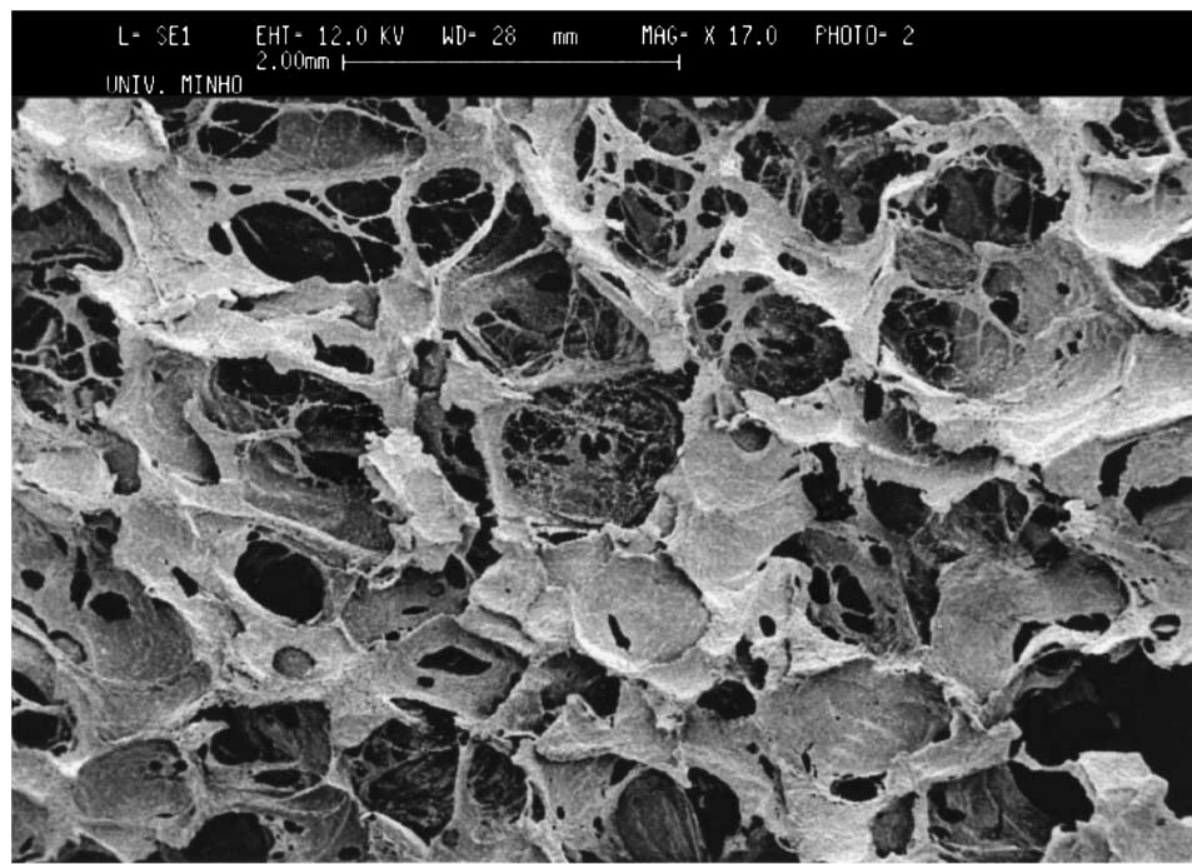

Fig. 3. Scaffold obtained by extrusion of SCA with $2 \%$ of blowing agent 3 (Hydrocerol BIH 40). 


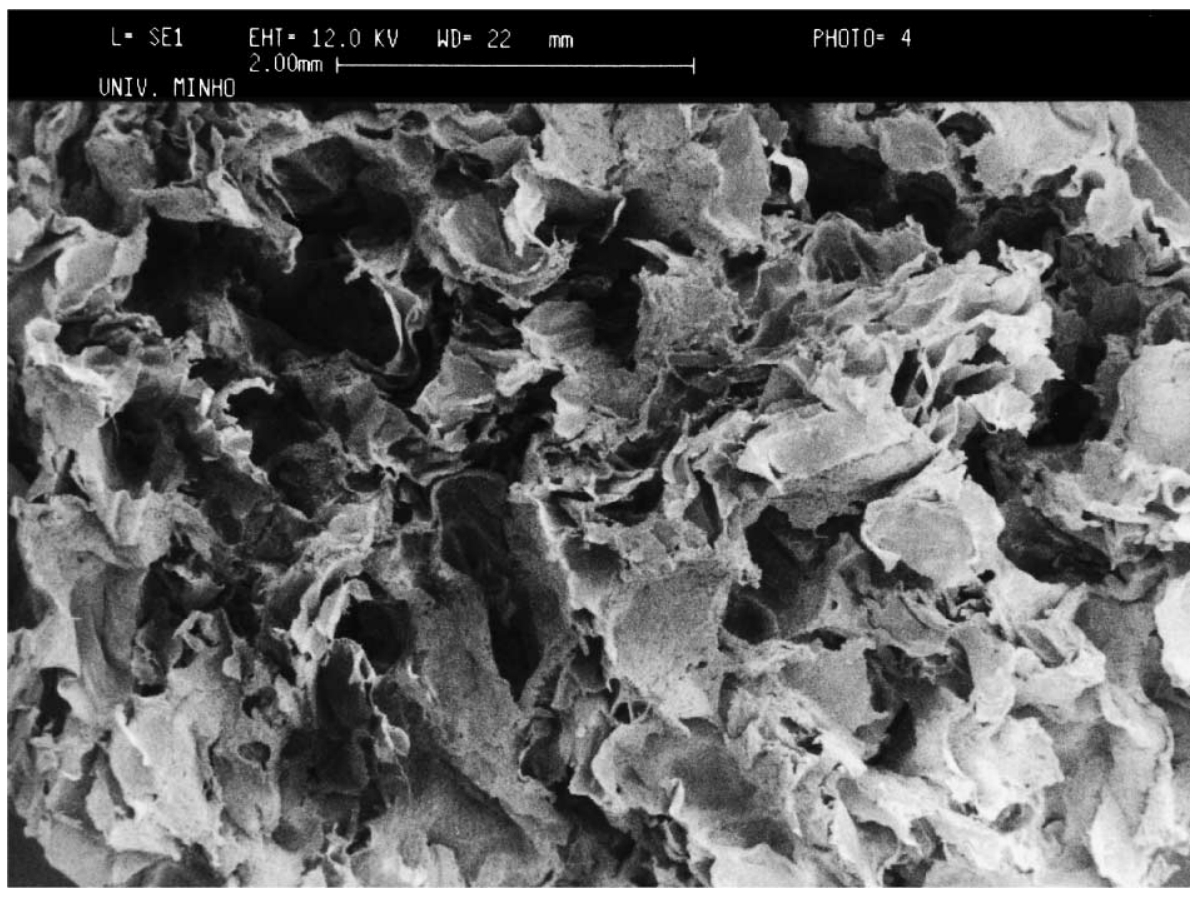

Fig. 4. Scaffold obtained by compression moulding + particle leaching of SCA with $65 \%$ of salt.

\subsubsection{Solvent casting and particle leaching}

The solvent casting and particle leaching method allowed to obtain an open-porous structure with a good interconnectivity between the pores throughout the entire structure (Fig. 6). In fact, these scaffolds presented the best interconnectivity achieved so far, with respect to the other processing methods. Furthermore, this method allows for the accurate control of the pore size, distribution of pore sizes and porosity (volume of voids). These parameters of the porous structure can be tailored by varying the size, shape and distribution of the particles and the chosen volume ratio of polymer/particles. The control of scaffold porosity is critical for controlling cellular colonization and organization within an engineered tissue.

The sample exhibited in Fig. 5 present a pore size between 50 and $300 \mu \mathrm{m}$. In these cases, the samples present a

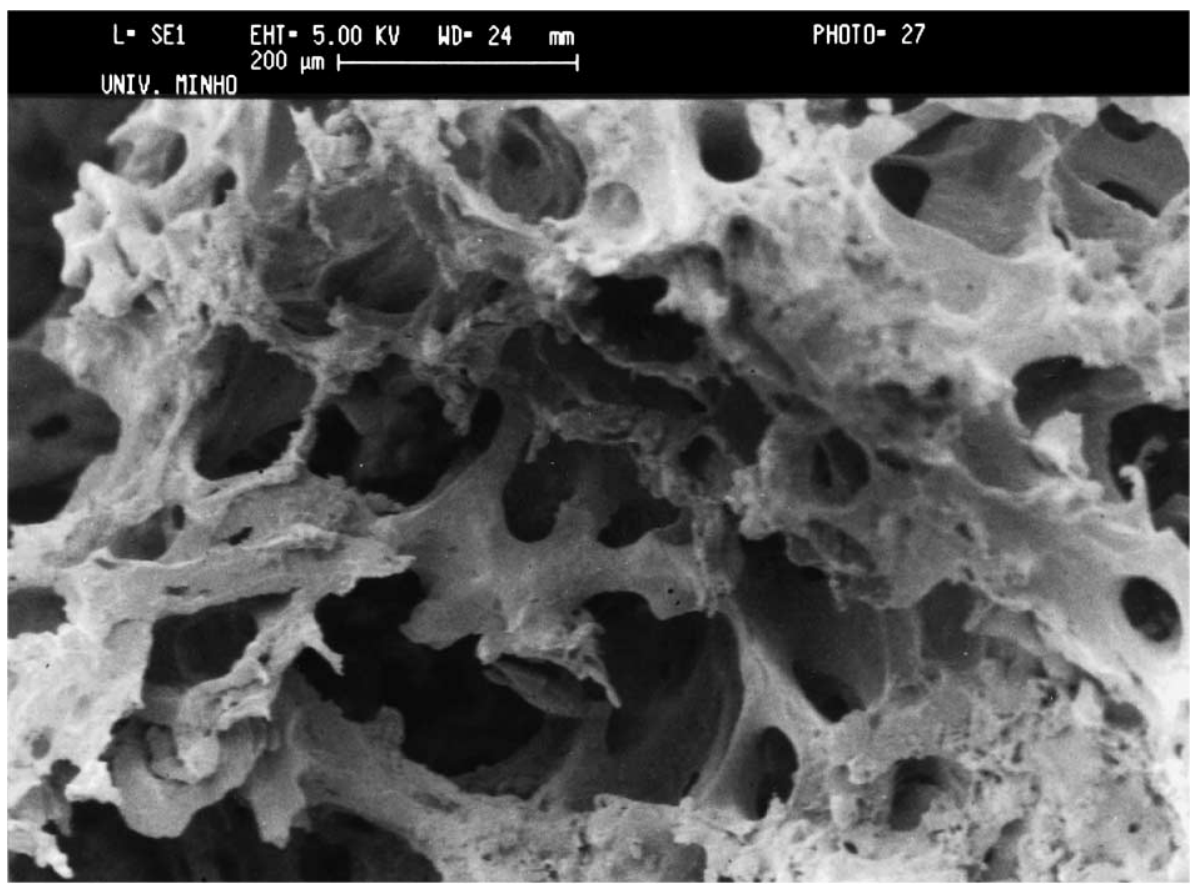

Fig. 5. Scaffold obtained by the solvent casting-particle leaching method. 


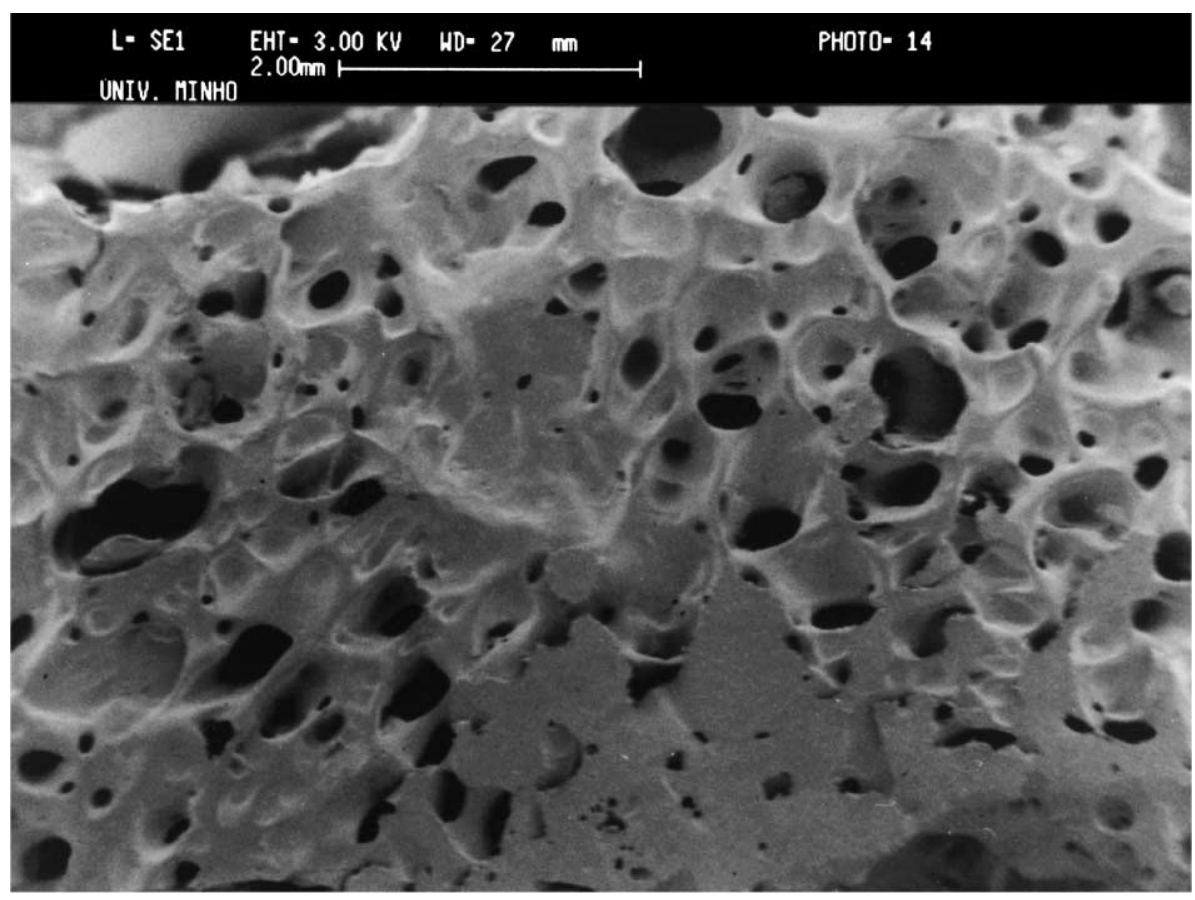

Fig. 6. Scaffold based on SEVA-C obtained by a method based on in situ polymerization.

density of about $0.6 \mathrm{~g} / \mathrm{cm}^{3}$, which leads to a porosity of around $60 \%$.

\subsubsection{In situ polymerization}

The innovation introduced by the in situ polymerization method of obtaining scaffolds for tissue engineering lies in the fact that it is possible to produce the scaffold in situ, i.e., it might be possible to inject the scaffold directly into the defect to treat, which can therefore take immediately the shape of the defect.

These mouldable polymer scaffolds fitting to the threedimensional geometry of specific tissue defects are highly in demand for clinical applications due to the invasiveness of

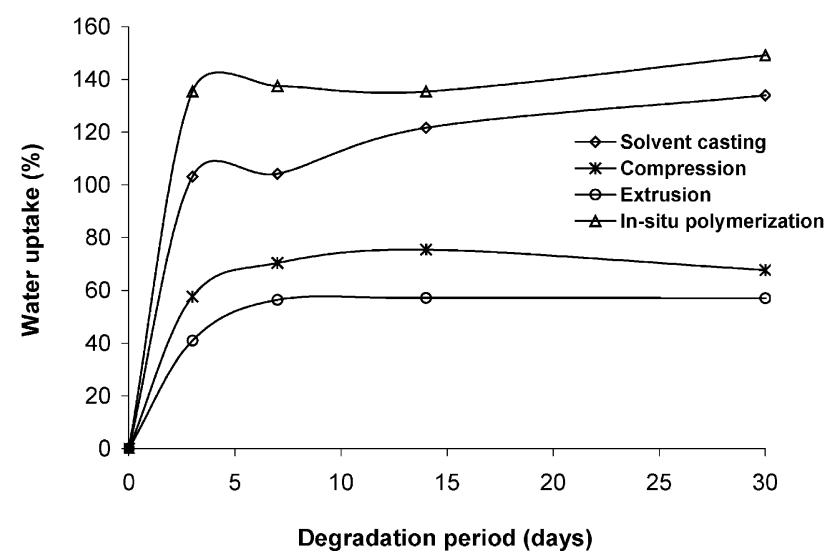

Fig. 7. Water uptake vs. degradation period for SCA-based scaffolds obtained by the different processing technologies developed. the surgical implantation procedure [26-28]. SEM analysis of this scaffolds showed pores ranging in size roughly from 10 to $100 \mu \mathrm{m}$ in diameter (Fig. 6), but once again, the pore size depends on the salt particles used.

\subsection{Degradation behaviour}

\subsubsection{Extrusion with blowing agents}

Figs. 7 and 8 show the water uptake and the weight loss as a function of the degradation period for the scaffolds obtained by the different processing methodologies developed.

As expected, the scaffolds obtained from the different methods presented similar water uptake and degradation

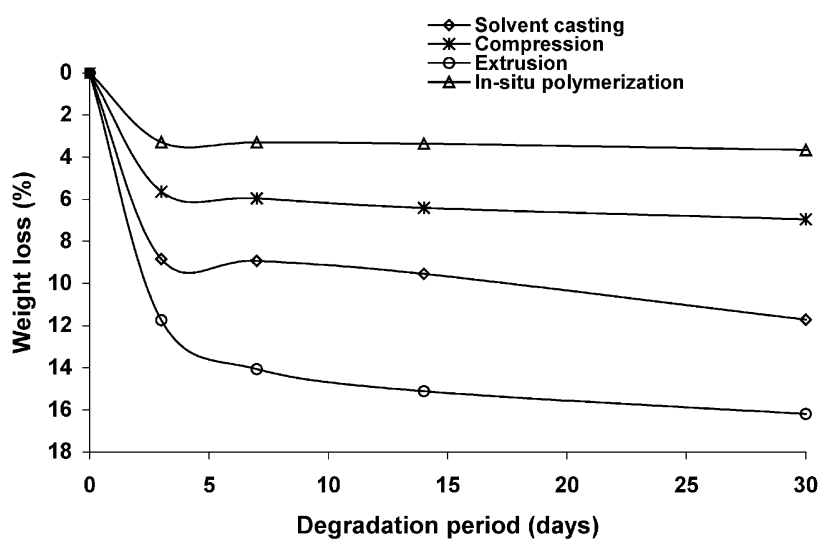

Fig. 8. Weight loss vs. degradation period for SCA-based scaffolds obtained by the different processing technologies developed. 
Table 1

Mechanical properties of the scaffolds obtained by the different processing methodologies developed

\begin{tabular}{|c|c|c|c|c|}
\hline Processing method & $\begin{array}{l}\text { Type and percentage of blowing } \\
\text { agent or porogen used }\end{array}$ & $\begin{array}{l}\text { Porosity of the } \\
\text { scaffolds }(\%)\end{array}$ & $\begin{array}{l}\text { Compressive } \\
\text { modulus (MPa) }\end{array}$ & $\begin{array}{l}\text { Compressive } \\
\text { strength (MPa) }\end{array}$ \\
\hline \multirow{5}{*}{ Extrusion with blowing agents } & 10\% Hostatron 9947 (BA1) & \multirow[t]{5}{*}{$40-50$} & $205.0 \pm 9.5$ & $12.0 \pm 1.4$ \\
\hline & 15\% Hostatron 9947 (BA1) & & $217.8 \pm 25.8$ & $17.6 \pm 0.9$ \\
\hline & 10\% Hostatron 9947 (BA1) + 1\% glycerol & & $230.8 \pm 71.0$ & $12.2 \pm 2.5$ \\
\hline & 2\% Hydrocerol BIH 70 (BA2) & & $172.4 \pm 35.5$ & $8.7 \pm 0.5$ \\
\hline & 2\% Hydrocerol BIH 40 (BA3) & & $124.6 \pm 27.2$ & $8.0 \pm 0.9$ \\
\hline \multirow{2}{*}{$\begin{array}{l}\text { Compression molding and } \\
\text { particle leaching }\end{array}$} & $50 \%$ of $\mathrm{NaCl}$ particles & \multirow[t]{2}{*}{$50-60$} & $341.6 \pm 34.3$ & $67.69 \pm 6.2$ \\
\hline & $65 \%$ of $\mathrm{NaCl}$ particles & & $133.7 \pm 20.6$ & $20.56 \pm 6.2$ \\
\hline Solvent casting and particle leaching & $60-70 \%$ of $\mathrm{NaCl}$ particles & $60-70$ & $170.5 \pm 16.09$ & $21.73 \pm 1.1$ \\
\hline
\end{tabular}

profiles although they exhibited different degradation rates and different water uptake ability, according to the processing method and conditions. As expected, the samples obtained using higher blowing agents fraction/higher salt particles fractions exhibit higher porosity. The different scaffolds' porosity attained by the different methods and also to the thickness of the outer solid layer will have direct influence in the ease of retention and access of the degradation solution in the bulk of the material, respectively, which will therefore influence their degradation behaviour.

The scaffolds obtained by the combination of compression moulding with particle leaching exhibit significantly higher water uptakes compared to samples obtained by extrusion with blowing agents, which demonstrates the higher porosity and interconnectivity achieved with this method. However, the weight loss of these scaffolds is lower than for the scaffolds obtained by extrusion, which is most probably due to thermo-mechanical degradation undergone by the materials processed by extrusion, which leads to an easier breakdown of the material (associated to leaching of low molecular weight chains).

The scaffolds obtained by the solvent casting and particle leaching exhibit very high water uptakes (more than 100\% after only days of immersion in the degradation medium), as compared to samples obtained by all the other processes. This is probably due to the high porosity and interconnectivity achieved with this method.

The scaffolds obtained by the in situ polymerization method present the highest water uptake ability since they have water uptake properties of hydrogels. Their degradation rates are obviously lower than those presented for the above scaffolds, since this final material is composed of a blend of the starch-based polymer with acrylic acid. The materials produced by this method are, in fact, not totally degradable, but they might be very useful in situations where it is necessary, high mechanical properties and/or in situations where the defect or trauma that is necessary to treat is of difficult access, avoiding highly invasive surgery techniques.

Furthermore, it is also possible to easily incorporate HA in the materials formulation, improving, at the same time, their mechanical properties and biological behaviour. This will be reported in a future paper.

\subsection{Mechanical properties}

The scaffolds obtained by extrusion with blowing agent 1 present the best compression properties, with a modulus varying from 205 to $230 \mathrm{MPa}$.

The blowing agents 2 and 3 gave rise to lower mechanical properties, probably due to the higher porosity and interconnection between pores that was achieved with these blowing agents, although these porous structures are more adequate for the final application of the scaffolds.

Nevertheless, these scaffolds present very promising mechanical properties when compared to other scaffolds obtained from other biodegradable polymers and proposed for use in tissue engineering of bone. For example, PLLA/ hydroxyapatite composite foams, prepared by a process based on phase separation, presented a compression modulus below $12 \mathrm{MPa}$ [29]. The results presented in Table 1 might be further improved by reinforcing the scaffolds with hydroxyapatite.

The compressive properties of the scaffolds obtained by compression moulding and particle leaching are also very dependent on the porosity obtained, being in some cases, superior to those obtained by the extrusion process.

As should be expected, the mechanical properties of the scaffolds obtained by the solvent casting and particle leaching method are lower when compared to the properties of the samples obtained by melt-based technologies. However, these properties may be considered very good when compared to scaffolds obtained from other materials by identical processing methods and proposed for the same type of applications. For example, a PLGA scaffold obtained by the solvent casting and particle leaching method exhibits a modulus of 1.09 MPa [30].

\section{Conclusions}

It was possible to develop a wide range of processing methods to obtain starch-based tissue engineering scaffolds. These scaffolds present adequate porous structure that can be tailored according to the intended application, with pore sizes in the range of those which are believed to be the most 
appropriate for bone cell culturing and/or bone tissue ingrowth. The interconnectivity obtained is dependent on the processing method. In general, the methods based on compression or solvent casting associated with particle leaching allowed to obtain the best interconnectivity between pores.

With respect to the degradation behaviour, although the profile is similar to all types of samples, the degradation rates can be significantly different depending on the processing method and on the final porosity obtained.

The mechanical properties of the scaffolds obtained by melt-based methods are the highest ones compared to the scaffolds obtained by the other methods, but in general, all the starch-based scaffolds present better mechanical properties than those reported in the literature for scaffolds obtained from other biodegradable polymers and proposed for bone tissue engineering applications.

The methods detailed herein allow for the optimisation of the porous structure, degradation kinetics and mechanical behaviour of starch-based scaffolds for a given application within the bone tissue engineering field. Therefore, scaffolds obtained from these materials using one of the described methodologies may constitute an important alternative to the materials currently used in tissue engineering.

\section{References}

[1] L.E. Freed, Vunjak-Novakovic, Culture of organized cell communities, Adv. Drug Delivery Rev. 33 (1998) 15-30.

[2] R.C. Thomson, M.C. Wake, M. Yaszemski, A.G. Mikos, Biodegradable polymer scaffolds to regenerate organs, Adv. Polym. Sci. 122 (1995) 247-274.

[3] R. Langer, Selected advances in drug delivery and tissue engineering, J. Controlled Release 62 (1999) 7-11.

[4] R. Langer, J.P. Vacanti, Tissue engineering, Science 260 (1993) 920925.

[5] R. Zhang, P.X. Ma, Poly( $\alpha$-hydroxyl acids)/hydroxyapatite porous composites for bone-tissue engineering: I. Preparation and morphology, J. Biomed. Mater. Res. 44 (1999) 446-455.

[6] W.W. Minuth, M. Sittinger, S. Kloth, Tissue engineering generation of differentiated artificial tissues for biomedical applications, Cell Tissue Res. 291 (1998) 1-12.

[7] E. Piskin, Biomaterials in different forms tissue engineering - an overview, Mater. Sci. Forum 250 (1997) 1-14.

[8] C.M. Agrawal, K.A. Athanasiou, J.D. Heckman, Biodegradable PLAPGA polymers for tissue engineering in orthopaedics, Mater. Sci. Forum 250 (1997) 115-228.

[9] N. Rotter, J. Aigner, A. Nauman, H. Planck, C. Hammer, G. Burmester, M. Sittinger, Cartilage reconstruction in head and neck surgery: comparison of resorbable polymer scaffolds for tissue engineering of human septal cartilage, J. Biomed. Mater. Res. 42 (1998) 347-356.

[10] J.C. Middleton, A.J. Tipton, Synthetic biodegradable polymers as orthopaedic devices, Biomaterials 21 (2000) 2335-2346.
[11] C.A. Vacanti, L.J. Bonassar, An overview of tissue engineered bone, Clin. Orthop. Relat. Res. 367S (1999) 375-381.

[12] B.S. Kim, D. Mooney, Development of biocompatible synthetic extracellular matrices for tissue engineering, TIB TECH 16 (1998) 224230.

[13] M.S. Chapekar, Tissue engineering: challenges and opportunities, J. Biomed. Mater. Res. (Appl. Biomater.) 53 (2000) 617-620.

[14] R. Thomson, M. Yaszemski, J. Powers, A. Mikos, Fabrication of biodegradable scaffolds to engineer trabecular bone, J. Biomater. Sci. Polym. Ed. 7 (1995) 23-38.

[15] D.W. Hutmacher, Scaffolds in tissue engineering bone and cartilage, Biomaterials 21 (2000) 2529-2543.

[16] L.E. Freed, G. Vunjak-Novakovic, R. Biron, D. Eagles, D. Lesnoy, S. Barlow, R. Langer, Biodegradable polymers scaffolds for tissue engineering, Bio/Technology 12 (1994) 689-693.

[17] K. Whang, K.E. Healy, D.R. Elenz, et al., Engineering bone regeneration with bioabsorbable scaffolds with novel microarchitecture, Tissue Eng. 5 (1999) 35-51.

[18] B. Saad, G. Ciardelli, S. Matter, et al., Degradable and highly porous polyesterurethane foam as biomaterial: effects and phagocytosis of defradation products in osteoblasts, J. Biomed. Mater. Res. 39 (1998) 594-602.

[19] D.W. Hutmacher, S.H. Teoh, I. Zein, M. Renawake, S. Lau, Tissue engineering research: the engineer's role, Med. Device Technol. 1 (2000) 33-39.

[20] R. Thomson, M. Yaszemski, A. Mikos, Polymer scaffold processing, in: R. Lanza, R. Langer, W. Chick (Eds.), Principles of Tissue Engineering, Academic Press, New York, 1997, pp. 263-272.

[21] M.E. Gomes, R.L. Reis, A.M. Cunha, C.A. Blitterwijk, J.D. de Bruijn, Cytocompatibility and response of osteoblastic-like cells to starch based materials: effects of several additives and processing conditions, Biomaterials 22 (2001) 1017-1911.

[22] I. Espigares, C. Elvira, J.F. Mano, J. San Román, R.L. Reis, New biodegradable and bioactive acrylic bone cements based on starch blends and ceramic fillers, Biomaterials 2001, submitted for publication.

[23] L. Lu, A. Mikos, The importance of new processing techniques in tissue engineering, MRS Bull. 21 (1996) 28-32.

[24] H. Kim, J. Smith, R. Valentini, Bone morphogenetic protein 2-coated porous poly-L-lactic acid scaffolds: release kinetics and induction of pluripotent C3H10T1/2 cells, Tissue Eng. 4 (1998) 35-51.

[25] K. Whang, K.E. Healy, D.R. Elenz, et al., Engineering bone regeneration with bioabsorbable scaffolds with novel microarchitecture, Tissue Eng. 5 (1999) 35-51.

[26] A. Burkoth, K. Anseth, A review of photocrosslinked polyanhydrides: in situ forming degradable networks, Biomaterials 21 (2000) 23952404.

[27] J.S. Temenhoff, A.G. Mikos, Injectable materials for orthopaedic tissue engineering, Biomaterials 21 (2000) 2405-2412.

[28] S. He, M. Yaszemski, A. Yasko, P. Engel, A. Mikos, Injectable biodegradable polymer composites based on poly(propylene fumarate) crosslinked with poly(ethylene glycol)-dimethacrylate, Biomaterials 20 (2000) 2389-2394.

[29] R. Zhang, P.X. Ma, Poly( $\alpha$-hydroxyl acids $) /$ hydroxyapatite porous composites for bone-tissue engineering: I. Preparation and morphology, J. Biomed. Mater. Res. 44 (1999) 446-455.

[30] Y.S. Nam, J.J. Yoon, T.G. Park, A novel fabrication method of macroporous biodegradable polymer scaffolds using gas foaming salt as a porogen additive, J. Biomed. Mater. Res. (Appl. Biomater.) 53 (2000) $1-7$. 